\section{Bovine Aortic Arch}

I knew that the congenital variation of the human aortic arch, with the left common carotid artery originating from the innominate artery, has nothing to do with the anatomy of the bovine arch; however, it was very useful of Layton et $\mathrm{al}^{1}$ to point out the discordance of the anatomic terminology. The weakness of the article, though, is that the authors did not trace who introduced and coined the term bovine arch. It would be very strange if that person did not know the anatomy of the aortic arch in the cow. Has it ever occurred to the authors that the originator of the term bovine arch did not have anatomy on his mind, but the appearance-head of the cow, 2 horns?

\section{Reference}

1. Layton KF, Kallmes DF, Cloft HJ, et al. Bovine aortic arch variant in humans: clarification of a common misnomer. AJNR Am J Neuroradiol 2006;27:1541-42

Jiri J. Vitek

Department of Interventional Neuroradiology Lenox Hill Heart and Vascular Institute of New York New York, NY

DOI 10.3174/ajnr.A0565

\section{Reply:}

We appreciate the interest and comments by Dr. Vitek regarding our $\operatorname{article}^{1}$ on the misnomer of the so-called "bovine aortic arch" variant in humans. As mentioned by Dr. Vitek, we were unable to discover who originally coined the term "bovine arch." However, this was not due to a lack of effort on the part of the authors. In fact, we polled a number of the most "seasoned" neuroradiologists around the country, and none of them knew the origin of the term. We also interrogated a multitude of articles and texts on the subject of human aortic arch variations, dating back to the early 1900s. Unfortunately, these were also unrevealing.

We agree that it is strange that someone would name this particular aortic arch variation in humans a "bovine arch" without knowing the aortic arch configuration of a cow. We really have no idea what the person who coined the term had in mind; therefore, the continued use of this term is of no clear value. As for Dr. Vitek's assumption that the bovine arch was intended to describe the appearance of a cow's head with horns, resemblance is clearly in the eye of the beholder. Growing up, I (K.F.L) spent many days working with cattle on a farm in rural Oklahoma. I am quite certain I have never seen a cow's head that resembles the bovine arch variant.

\section{Reference}

1. Layton KF, Kallmes DF, Cloft HJ, et al. Bovine aortic arch variant in humans: clarification of a common misnomer. AJNR Am J Neuroradiol 2006;27:1541-42

K.F. Layton

Department of Radiology

Baylor University Medical Center

Dallas, Tex

H.J. Cloft

E.P. Lindell

D.F. Kallmes

Department of Radiology

Mayo Clinic

Rochester, Minn

DOI 10.3174/ajnr.A0671

\section{Cystic Intraventricular Solitary Fibrous Tumor}

We read with interest the article by Surendrababu et al $^{1}$ about an unusual case of a solitary fibrous tumor (SFT) located at the atrium of the left lateral ventricle in an adult. Although rare, intraventricular SFTs have been described previously in the lateral ventricles, the third and fourth ventricles, ${ }^{2,3}$ where they certainly develop from the perivascular connective tissue of the choroid plexus. Preoperative diagnosis is challenging, because highly specific imaging features of SFTs have not been described. Surendrababu et $\mathrm{al}^{1}$ emphasize that SFTs are hyperintense on T2weighted images. To the contrary, we think that they should have placed greater emphasis on the diagnostic value of SFT low T2 signal intensity. The lack of MR images in their case is troubling, because MR imaging may have demonstrated this important differential diagnostic feature. Indeed, low T2 signal intensity, corresponding with areas composed of interlacing bundles of spindle cells ${ }^{4}$ or collagenous septations, ${ }^{3}$ has frequently been reported in SFTs and is considered to be a suggestive feature of the diagnosis. ${ }^{3-5}$ We agree with the authors, however, that MR patterns of SFTs are variable, including T2 hyperintensity and/or cystic component, even when the mass is intraventricular.

To reinforce this idea, we illustrate the case of a 44-year-old woman with a multicystic SFT in the right lateral ventricle who presented with right retro-orbital pain and seizure. This multiloculated mass was hypointense on T1-weighted images, hyperintense on T2weighted images, and demonstrated thin peripheral enhancement of multiple confluent cysts after gadolinium administration (Fig 1A). Histopathologic examination showed spindle cells, and immunohistochemistry was strongly positive for CD34, confirming the diagnosis of SFT (Fig 1B). The case described by Surendrababu et $\mathrm{al}^{1}$ and ours both emphasize the fact that intracranial SFT is an emerging entity

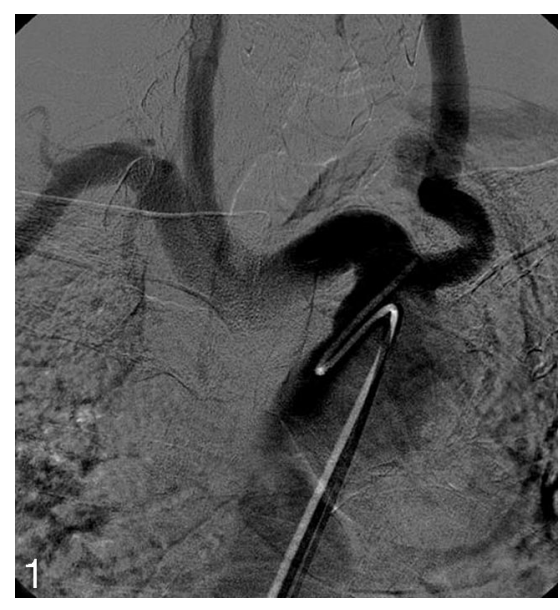

Fig 1. So-called bovine aortic arch.

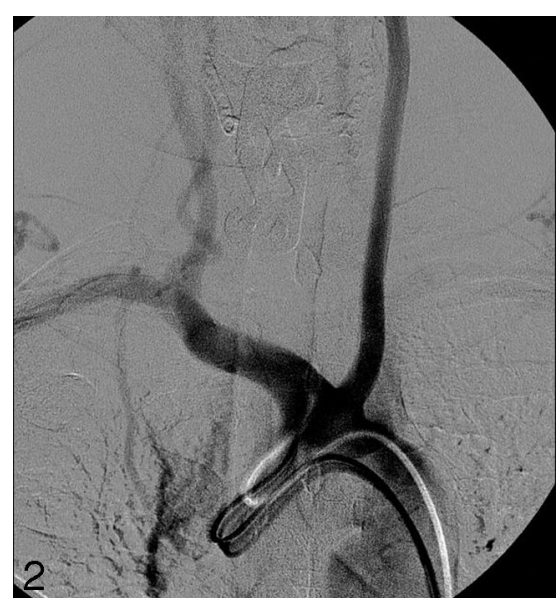

Fig 2. So-called bovine aortic arch.

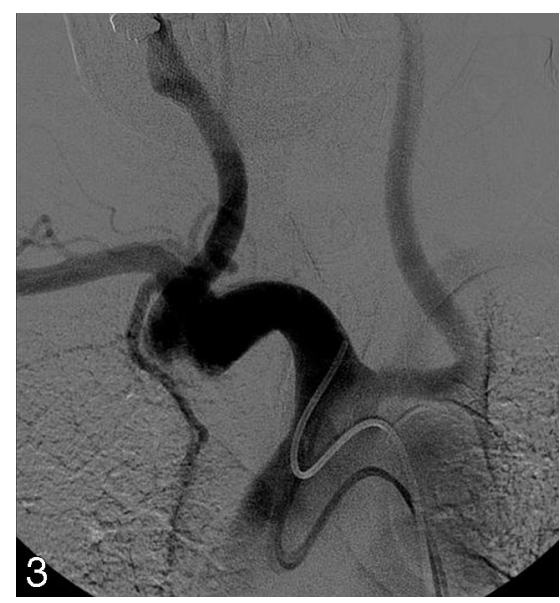

Fig 3. So-called bovine aortic arch. 

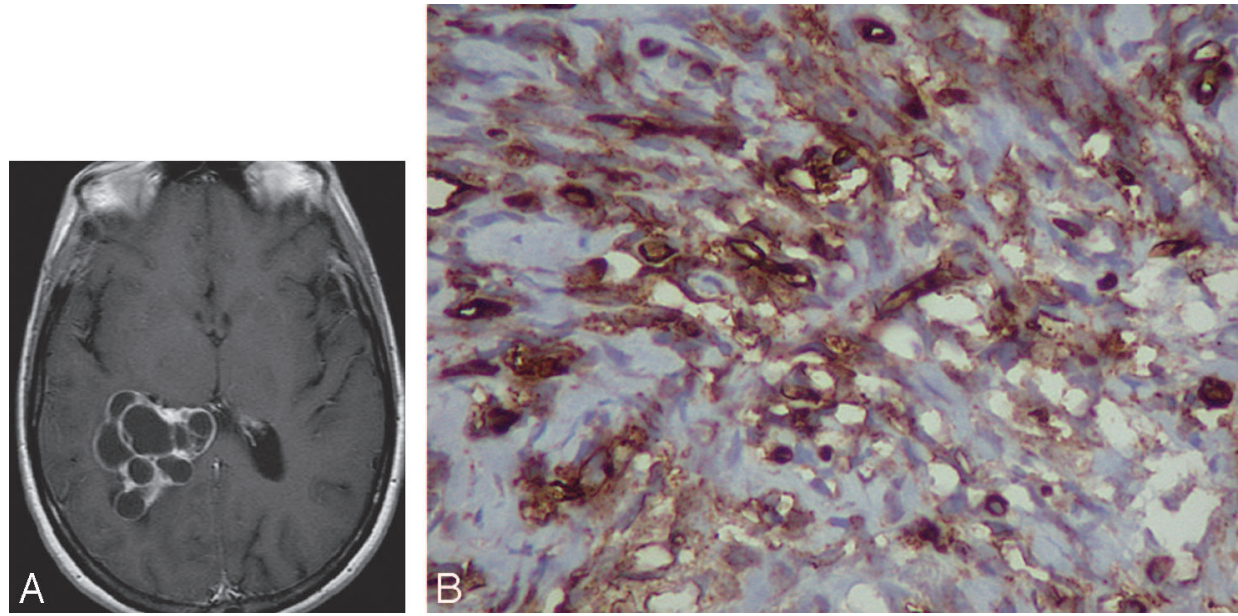

Fig 1. A, Axial contrast-enhanced T1-weighted image shows a multiloculated cystic solitary fibrous tumor in the right lateral ventricle. $B$, Histologic examination demonstrates marked anti-CD34 immunopositivity.

that is diagnosed more frequently, especially in the cerebral ventricles. It is important to understand and recognize the protean nature and imaging polymorphism of this tumor.

\section{Acknowledgment}

We are indebted to David Seidenwurm, MD, for his help in writing this letter.

\section{References}

1. Surendrababu NR, Chacko G, Daniel RT, et al. Solitary fibrous tumor of the lateral ventricle: $\mathrm{CT}$ appearances and pathologic correlation with follow-up. AJNR Am J Neuroradiol 2006;27:2135-36

2. Kocak A, Cayli SR, Sarac K, et al. Intraventricular solitary fibrous tumor: an unusual tumor with radiological, ultrastructural, and immunohistochemical evaluation: case report. Neurosurgery 2004;54:213-16

3. Clarençon F, Bonneville F, Sichez JP, et al. Atypical location of a solitary fibrous tumor in the fourth ventricle. J Neuroradiol 2006;33:279-80

4. Sa G, Bonneville F, Poirier J, et al. Giant solitary fibrous tumour of the meninges: MR-pathological correlation. J Neuroradiol 2006;33:343-46

5. Nawashiro H, Nagakawa S, Osada H, et al. Solitary fibrous tumor of the meninges in the posterior cranial fossa: magnetic resonance imaging and histological correlation-case report. Neurol Med Chir 2000;40:432-34

Frédéric Clarençon

Fabrice Bonneville

Jacques Chiras

Department of Neuroradiology

Michèle Kujas

Department of Neuropathology

Philippe Cornu

Department of Neurosurgery

Hospital of the University of Pitié-Salpêtrière Assistance Publique-Hôpitaux de Paris Paris, France

\section{DOI 10.3174/ajnr.A0572}

\section{Reply:}

We thank the authors for commenting on our case report. ${ }^{1}$ They present an interesting and well-documented case of a solitary fibrous tumor (SFT) in the atrium of the right lateral ventricle to add to the previous cases of intraventricular SFTs in the literature. ${ }^{2}$ The unusual feature of their tumor was its multiloculated cystic nature with enhancing septations. Evidently, the increased awareness among pathologists of intracranial and spinal SFTs may result in the diagnosis being made more frequently. Of clinical relevance is that SFTs, though usually indolent, can behave aggressively with symptomatic recurrences requiring a second surgery or adjunctive radiation therapy. ${ }^{3}$ Although we agree that MR imaging may have demonstrated T2 hypointensity in our case, due to the presence of calcification, it is unlikely that we could have ruled out a meningioma or a choroid plexus papilloma on that basis alone. As the authors emphasize, the MR imaging features of SFTs are so variable that it would be difficult to differentiate these tumors from meningiomas, hemangiopericytomas, or gliomas with any degree of certainty.

\section{References}

1. Surendrababu NR, Chacko G, Daniel RT, et al. Solitary fibrous tumor of the lateral ventricle: $\mathrm{CT}$ appearances and pathologic correlation with follow-up. AJNR Am J Neuroradiol 2006;27:2135-36

2. Gessi M, Lauretti L, Fernandez E, et al. Intraventricular solitary fibrous tumor: a rare location for a rare tumor. J Neurooncol 2006;80:109-10

3. Caroli E, Salvati M, Orlando ER, et al. Solitary fibrous tumors of the meninges: report of four cases and literature review. Neurosurg Rev 2004;27:246-51

A.G. Chacko

R.T. Daniel

Department of Neurological Sciences Section of Neurosurgery

G. Chacko

Department of Neurological Sciences Section of Neuropathology

N.R.S. Surendrababu Department of Neurological Sciences Section of Radiodiagnosis Christian Medical College Tamil Nadu, India

DOI 10.3174/ajnr.A0615

\section{Erratum}

We are deeply grateful to AJNR for publishing our article (Shouyama M, Kitabata Y, Kaku T, et al. Evaluation of Regional Cerebral Blood Flow in Fahr Disease with Schizophrenia-Like Psychosis: A Case Report. AJNR Am J Neuroradiol 2005;26:2527-29). Unfortunately, one of the author's names was improperly converted from Japanese to English spelling. I would like to correct the spelling as it appears in the list of authors from "Masaru Shouyama" to "Masaru Shoyama."

Masaru Shoyama

Neuropsychiatry

Wakayama Medical University

Wakayama, Japan

DOI 10.3174/ajnr.A0764 